\title{
Empirical Study on the Influencing Factors of the Level of the Development Urbanization Based on MLR Model
}

\author{
Wu Jianrong \\ Department of Mangement, Chongqing Radio \& TV Universtiy, Chongqing, China \\ Email address: \\ 137859456@qq.com \\ To cite this article: \\ Wu Jianrong. Empirical Study on the Influencing Factors of the Level of the Development Urbanization Based on MLR Model. Humanities \\ and Social Sciences. Vol. 8, No. 1, 2020, pp. 1-6. doi: 10.11648/j.hss.20200801.11
}

Received: December 22, 2019; Accepted: January 21, 2020; Published: February 3, 2020

\begin{abstract}
China began to enter the new era of urbanization with the core of improving the quality of urbanization. In this paper, the validity of influencing factors of urbanization development level is seldom studied. Starting from the influencing factors of urbanization development level, using qualitative and quantitative methods, based on theoretical as sumptions, a measurement model of influencing factors of urbanization development level is constructed. SPSS 19.0 statistical software is used to analyze the panel data of 23 administrative regions in Chongqing. The empirical results show that the urbanization rate, the degree of urban-rural coordination, the efficiency of urbanization, the qualit $y$ of urban development on the level of urbanization development in turn decline. On the basis of the analysis of the empirical results, this paper puts forward relevant policy recommendations to enhance the level of urbanization, which has a certain guiding significance and role for the current urbanization construction in China.
\end{abstract}

Keywords: Level of the Development Urbanization, Influencing Factors, MLR Model, Validity

\section{Introduction}

Party 18 report put forward the new idea of urbanization development: promoting benign interaction of urbanization and industrialization, urbanization and agricultural modernization coordination, promote industrialization, informatization, urbanization and agricultural modernization "four modernizations" synchronous development, clearly put forward the economy under the new normal "obviously improve the quality of urbanization" new requirements. By the 17 th national congress of the proportion of urban residents will notably increase to the eighteenth big "obviously improve the quality of urbanization", means that China has entered the new era of urbanization in order to improve the quality of urbanization as the core. The national civilized city assessment standard requires the assessment of the civilization degree of the city from the economic, political, cultural, ecological and harmonious society, which is the evaluation index of the level of urbanization development. Luo chunhui [1] constructed the indicators of influencing factors of urbanization development level from the three dimensions of basic level, comprehensive level and social development level, and conducted relevant tests. "China's urbanization quality report" [2] that quality of urbanization is to point to in the process of urbanization and urbanization relatively reflect the good and bad level of the urbanization level of a comprehensive concept, especially the development of the various elements of urbanization quality, coordination degree and propulsive efficiency. Wu jianrong [3] the research achievements of many scholars at home and abroad for reference, combines the single index method and the composite index method, selection and urban development quality and efficiency of the propulsion of urbanization, urban and rural coordination degree is related to several factors as a measure of quality of urbanization construction based on the quantity and quality of urbanization a function of two dimensions to evaluate the level of urbanization development.

Researchers from all walks of life to the urbanization development level of the study of influencing factors and measure the paper improves the theoretical guidance for further study, but the existing research, more is the establishment of evaluation index system of measure of influence factors of urbanization, or qualitatively the influence factors. On the basis of summarizing the existing research, this paper research on the influence factor of urbanization development level on the one hand, follow the number of 
indicators reflect the urbanization development level, on the other hand take into account the new urbanization "urban construction in urban and rural areas as a whole, urban and rural integration" connotation of the quality requirements.

\section{The Main Influencing Factors, Theoretical Hypothesis and Model Construction}

\subsection{The Main Influencing Factors of Urbanization Development Level}

\subsubsection{Urbanization Rate}

The urbanization rate is an evaluation index that reflects the level of urbanization development in quantity. Generally speaking, the percentage of the urban population in the area is used to reflect the process and concentration of the population to the city. The urbanization rate is also an important indicator to measure the level of social organization and management in a country or region.

Hypothesis 1: urbanization rate is positively correlated with the level of urbanization development.

\subsubsection{The Development Quality of the City Itself}

After Wu jianrong reference, Wei Hou kai, Wang Yejiang, Su Gongjian, kay Guo Yebo [4] and others thought that the development of the city's own quality from three aspects economic, social and ecological measure. In particular, should use per capita GDP, non-agricultural industry share of GDP, urban residents engel's coefficient, the per capita fiscal expenditure on education, public library, one hundred people, one thousand people have beds digits, urban community service facilities for ten thousand people, the greening coverage such as index to reflect the development of the city's own quality level.

Hypothesis 2: the development quality of the city itself is positively correlated with the level of urbanization development.

\subsubsection{The Efficiency of Urbanization}

The efficiency of urbanization includes economic and social efficiency and ecological environment efficiency. Among them, economic and social efficiency includes unit labor, fixed asset investment, GDP of built-up area and the number of urban population absorbed by unit built-up area. The eco-environmental efficiency includes the energy consumption per unit of GDP and the degree of pollution to the environment.

Hypothesis 3: the efficiency of urbanization is positively correlated with the level of urbanization development.

\subsubsection{The Degree of Urban and Rural Coordination}

The degree of urban-rural coordination includes two aspects: income coordination and public service coordination. Among them, income coordination includes the income disparity between urban and rural residents and the change of urban and rural engel coefficient. The coordination of public services includes the proportion of public service resources and residents enjoyed by residents in the area.

Hypothesis 4: the degree of urban-rural coordination is positively correlated with the level of urbanization development.

\subsection{Model Building}

According to the above theoretical assumptions, the variables and instructions selected in this paper are shown in table 1.

Table 1. Variable selection and instructions.

\begin{tabular}{|c|c|c|c|}
\hline serial number & variable & variable symbol & explain \\
\hline 1 & Urbanization development level & $\mathrm{L}$ & Explained variable \\
\hline 2 & Urbanization rate & $\mathrm{R}$ & Explanatory variable \\
\hline 3 & The development quality of the city itself & Q & Explanatory variable \\
\hline 4 & The efficiency of urbanization & $\mathrm{E}$ & Explanatory variable \\
\hline 5 & The degree of urban and rural coordination & $\mathrm{D}$ & Explanatory variable \\
\hline
\end{tabular}

Multivariate linear model is a dependent variable, and study two or more than two independent variables of regression analysis method, which reflects the number of a phenomenon or things according to the number of a variety of phenomenon or things of the law of the change and change accordingly. Excluding the other factors that have little impact on urbanization development level, this paper constructs the following measurement model:

$$
L_{i t}=\beta_{0}+\beta_{1} R_{i t}+\beta_{2} Q_{i t}+\beta_{3} E_{i t}+\beta_{4} D_{i t}+\mu_{i t}
$$

Among them, $i, t$ represent cities and periods, $\beta_{0}$ is the constant term, $\beta_{1}, \beta_{2}, \beta_{3}, \beta_{4}$ Respectively represent the impact coefficient of each city on the urbanization rate, the development quality of the city itself, the efficiency of urbanization promotion and the degree of urban-rural coordination to the level of urbanization development. $\mu$ is a random disturbance term.

\subsection{Empirical Analysis of the Model}

Based on 23 administrative region in chongqing, wanzhou district, qianjiang, fuling, yuzhong district, dadukou district, jiangbei, shapingba district, jiulongpo district, nanan distract, beibei district, yubei district, banan district, changshou district, metro, ocean area, yongchuan district, nanchuan district, qijiang district, dazu county area, bishan area, TongLiang area, model. flood-control area, for prosperity area) as the research object. The main data came from the statistics of chongqing statistical yearbook [5] and related website statistics of the administrative region. By Pannel Data of each index in the 
content, dimension and quality standards are different aspects of value, so it is necessary to convert various indexes into relatively uniform scale, standardization of Data processing, its purpose is to eliminate the variable values in the order of magnitude differences between variables, so as to enhance the comparability between Data. The standardization process is as follows:

$$
y_{j}=\frac{z_{j}-z}{\sigma}(j=1,2,3 \ldots \ldots)
$$

$y_{i}$ is the result of standardized processing of indicators, $z_{j}$ is the original observation, $z$ is the mean of the data, $\sigma$ is the standard deviation。

Based on the research object of data after dealing with the standardized, for the convenience of study, this paper uses the simple arithmetic average method, draw lessons from $\mathrm{Wu}$ jianrong [3] research results, generate 23 administrative region urbanization development level, urbanization rate and urban development quality and efficiency of the propulsion of urbanization, urban and rural coordination degree of characteristic values such as table 2 .

Table 2. Variable characteristic value.

\begin{tabular}{llllll}
\hline Variable administrative district & developmental level & urbanization rate & development quality & propulsive efficiency & urban-rural coordination \\
\hline yuzhong & 1.39 & 1.15 & 0.9 & -1.08 & -1.33 \\
dadukou & 1.69 & 1.37 & 0.36 & -1 & -0.29 \\
Jiangbei & 2.07 & 1.24 & 0.66 & 0.26 & 0.03 \\
shapingba & 0.33 & -0.07 & 1.26 & -1.24 & 0.13 \\
jiulongpo & 1.43 & 0.46 & 1.22 & 0.38 & 0.22 \\
nanan & 1.46 & 0.71 & 1.03 & 0.46 & -0.76 \\
beibei & 0.13 & 0.67 & -0.78 & -0.74 \\
yubei & 0.34 & 0.16 & -0.03 & -0.14 & 0.24 \\
banan & -0.45 & -0.86 & 0.64 & 0.16 & 0.81 \\
fuling & -0.68 & -1.11 & 0.7 & -0.09 & -0.26 \\
changshou & -0.48 & -0.73 & 0.31 & -0.07 & -0.39 \\
qijiang & -1.33 & -1.14 & -0.6 & -0.41 \\
hechuan & -1.48 & -0.72 & -0.5 & -0.16 & 0.27 \\
bishan & -0.16 & -0.41 & -0.23 & -1.27 \\
yongchuan & -1.08 & 0.05 & -0.89 & -1.03 \\
nanchuan & -1.24 & -0.35 & -0.01 & -1.2 & \\
qijiang & -0.53 & -0.39 & 0.12 & 0.56 \\
dazu & -0.93 & -0.67 & 0.07 & 0.54 & -1.39 \\
wanzhou & -0.54 & -0.55 & 0.64 & -22 & -0.25 \\
qianjiang & -0.04 & 0.35 & -0.8 & -0.56 & -0.14 \\
tongliang & 0.11 & -0.58 & -0.38 & -0.26 & -0.39 \\
tonglan & -0.25 & -0.46 & -0.66 & -0.36 & \\
rongchang & -0.44 & -0.92 & & \\
\hline
\end{tabular}

In this paper, SPSS 19.0 software was used to analyze the data, and its descriptive statistical results were shown in table 3 . The constructed model is estimated, and the regression results are shown in table 4, table 5, and table 6.

Table 3. Describe the statistic.

\begin{tabular}{llllll}
\hline & N & Min & Max & Mean value & Standard deviation \\
\hline The level of urbanization development & 23 & -1.48 & 2.07 & .0004 & .99930 \\
Urbanization rate & 23 & -1.15 & 1.37 & -.2452 & .79749 \\
Self-development quality & 23 & -.80 & 1.26 & .2130 & .61981 \\
To promote the efficiency & 23 & -1.24 & 1.22 & -.1652 & .58471 \\
Urban-rural coordination & 23 & -1.39 & .81 & -.3274 & .62879 \\
Valid N (list state) & 23 & & & & \\
\hline
\end{tabular}

Table 4. The model summary.

\begin{tabular}{lllll}
\hline Modle & $\mathbf{R}$ & $R^{2}$ & After the adjustment & $R^{2}$ \\
\hline 1 & $.978 \mathrm{a}$ & .957 & .947 & Error of standard estimate. \\
\hline
\end{tabular}

a. Prediction variables: (constant), urban-rural coordination degree, promoting efficiency, urbanization rate, self-development quality.

Table 5. Anova.

\begin{tabular}{llllll}
\hline Modle & & sum of squares & df & mean square & F \\
\hline \multirow{3}{*}{1} & regression & 21.014 & 4 & 5.254 & 99.035 \\
& residual & .955 & 18 & .053 & \\
& total & 21.969 & 22 & & $.000 \mathrm{a}$ \\
\hline
\end{tabular}

a. Prediction variables: (constant), urban-rural coordination degree, promoting efficiency, urbanization rate, self-development quality.

b. Dependent variable: urbanization development level. 
Table 6. The coefficient.

\begin{tabular}{|c|c|c|c|c|c|c|}
\hline \multirow{2}{*}{\multicolumn{2}{|c|}{ Modle }} & \multicolumn{2}{|c|}{ Nonstandardized coefficient } & \multicolumn{3}{|c|}{ The standard coefficient } \\
\hline & & B & Standard error & A trial version & t & Sig. \\
\hline \multirow{5}{*}{1} & (constant) & .399 & .079 & & 5.049 & .000 \\
\hline & Urbanization rate & 1.216 & .079 & .971 & 15.330 & .000 \\
\hline & Self-development quality & .168 & .103 & .104 & 1.635 & .119 \\
\hline & To promote the efficiency & .233 & .085 & .136 & 2.747 & .013 \\
\hline & Urban-rural coordination & .297 & .097 & .187 & 3.056 & .007 \\
\hline
\end{tabular}

a. Dependent variable: urbanization development level.

\subsection{Regression Analysis}

This regression analysis sample number $n=23$, Explanatory variable number $m=4$.

Assumptions: $H_{0}: \beta_{i}=0, H_{1}: \beta_{i}$ Not all zero. Through SPSS 19.0 analysis, the following inspection conclusions can be obtained:

1. Test of fitting degree:

$R^{2}=0.957$, After the adjustment $R^{2}=0.9477$, they are very close to 1 , It indicates that the fitting degree of the model is relatively ideal, and the level of urbanization is closely related to urbanization rate, urban development quality, urbanization promotion efficiency and urban-rural coordination degree.

\section{F test:}

The $\mathrm{F}$ test value shown in table 6 is. 99.035, $F_{0.05}$ (4, 23-4-1) $=2.928$, F test is far greater than the critical value, Reject the null hypothesis $H_{0}$, Accept the alternative hypothesis $H_{1}$, It is pointed out that the regression equation of urbanization development level and urbanization rate, urban development quality, urbanization promotion efficiency and urban-rural coordination degree is significant.

3. t-value test: Table 6 shows the regression coefficient. $\beta_{0}$ $=0.399, \beta_{1}=1.216, \beta_{2}=0.168, \beta_{3}=0.233, \beta_{4}=0.297$, The regression coefficient test value is respectively. 5.049, 15.330 , $1.635,2.747,3.056, t_{0.05}(23-4-1)=2.101$, The test value is greater than the critical value. So reject the original hypothesis. $H_{0}$, Accept the alternative hypothesis $H_{1}$, It can be concluded that urbanization rate, urban development quality, urbanization promotion efficiency and urban-rural coordination have significant impact on the level of urbanization development.

Combined with the above calculation results and test results, the following regression model can be obtained:

$$
L_{i t}=0.399+1.216 R_{i t}+0.168 Q_{i t}+0.233 E_{i t}+0.297 D_{i t}+\mu_{i t}
$$

By model (3) it can be seen that the urbanization rate and quality of urban development, promote the efficiency of urbanization, urban and rural coordination degree and urbanization development level was positively related, and through the test of significance. Said that under the condition of controlling other variables, the urbanization rate every $1 \%$ increase, the urbanization development level will increase $1.216 \%$, proved that the improvement of urbanization rate would lead to the urbanization development level, regression results support the theoretical hypothesis 1 . Quality every $1 \%$ increase in urban development, the urbanization development level will increase $0.168 \%$, prove city in economy, society and the development of space on the quality of urban development level, regression results support the theoretical hypothesis 2 . For every $1 \%$ increase in the efficiency of urbanization, the level of urbanization will be increased by $0.233 \%$. The regression results support the theoretical hypothesis 3. For every $1 \%$ increase in urban and rural coordination, the level of urbanization will increase by $0.297 \%$, and the regression results support the theoretical hypothesis 4 .

\section{Conclusions}

Validity reflects the degree of influence of the explanatory variable with causality on the explained variable. The larger the validity value is, the larger the influence degree is, and the smaller the value is, indicating that the degree of influence is smaller. Based on the analysis of the above, the urbanization development level and rate of urbanization, urban and rural coordination degree, efficiency of propulsion of urbanization, the city plays a significant role in the development of quality factors such as correlation, but affect the validity of the decline in turn. Therefore, while vigorously carrying out the construction of new-type urbanization all over the country, we should pay attention to the rational allocation of limited resources, make small efforts and improve the level of urbanization in a scientific and orderly way. Based on the above analysis conclusion, the author proposes the following policy Suggestions:

\subsection{We will Accelerate Reform of the Urban and Rural Household Registration System and Raise the Urbanization Rate}

The free migration and transfer of rural population to cities is the most effective means for China to improve the urbanization rate and accelerate the new urbanization process. [6] Cancel the agricultural registered permanent residence and non-agricultural registered permanent residence, unified registration for residents "hukou", which is represented by the provinces and cities of chengdu directly effective means, its successful place worth using for reference.[7] Of course, including the household registration, land, employment, social security, education, health care, housing and so on the size of the transfer cost directly affects the efficiency of the rural population transfer to the town, as a result, after the unification of residents "hukou", from the form can solve the problem of household registration system, to implement the residents 
from the system and mechanism of follow-up, the transfer of government should deepen the relevant system innovation, accelerate the orderly transfer of rural population, guarantee the transfer residents to local employment, to live and work in peace and contentment.

\subsection{We will Strengthen Social Service Management and Ensure Coordinated development Between Urban and Rural Areas}

First of all, while striving to increase the income of urban residents, we should promote the income level of rural residents, narrow the income gap between urban and rural residents, and reduce the proportion of household consumption expenditure as a share of income. [8] Second, improve the livelihood of the people accounts for the proportion of public fiscal expenditure, strengthen the public service facilities in the aspects such as education, health care coordination development, a comprehensive enhance the level of district residents enjoy equal basic public services, Earnestly solve the people focus on problems such as employment, housing, education, health care, steadily promote the reform of society, vigorously foster development of social organizations, foreign workers service management innovation, [9] to promote the urban and rural social security system and axle, actively explore to build collaborative work, benefit sharing of social governance model, so as to ensure the coordinated development of urban and rural areas.

\subsection{Intensive Development to Accelerate the Efficiency of Urbanization}

Habitable land resources, water resources shortage is one of China's basic national conditions, enhance the level of urbanization should be scientific and rational allocation of resources, adhere to the principle of population, resources, environment coordinated, sustainable development, intensive urbanization road.[10] On the one hand, the government should play the leading role of the government, strengthen the planning and design, optimize the urban and rural spatial layout, and pay attention to the resource intensive requirements of urban planning. Increase the GDP that can be produced by the input of resources such as people, wealth and things; On the other hand the government should strengthen the environmental protection guidance, pays special attention to the key field of energy conservation and emissions reduction, reducing energy consumption, the new technology, new material, new energy use should have advanced adaptive, on the basis of advocating the harmony between nature and society, reasonable and effective improve the efficiency of land use or volume rate, enhance the level of city purification, greening and beautification. [11]

\subsection{We will Accelerate the Development of the Tertiary Industry and Promote the Quality of Urban Development}

China has just entered the mid-term stage of industrialization,[12] industrialization of boost demand and structure change will cause the production and living services as the main content of the third industry structure on the expansion and the enlargement of the proportion [13], so that the third industry become the subsequent urbanization development momentum.[14] China's tertiary industry now accounts for about 40 per cent of GDP, compared with about 60-80 per cent in developed countries. Therefore, the government should be to speed up the development of tertiary industry as the breakthrough point, first of all, to improve jurisdiction of GDP per capita GDP and non-agricultural industry, secondly,[15] increase investment in education, health care and infrastructure services building, third, should increase the intensity of environmental governance, improve the district greening coverage, so as to promote the urbanization quality improvement.[16]

\section{Fund Project}

Part of the research results of chongqing education commission's 2014 science and technology research project "chongqing urbanization quality research" (subject No.: kj1403801), by associate professor wu jianrong. Deals with the research on the layout and structure adjustment of Higher Vocational Education in Chongqing under the background of new urbanization (subject No. 19SKGH271), the research on the teaching reform of higher education of Chongqing Municipal Education Commission (subject No.: 183258).

\section{References}

[1] Luo chunhui (2011). Verification and analysis of influencing factors of urbanization development level. Anhui agriculture bulletin, 15-18.

[2] Xin Yu yan (2013). New-type urbanization -- theoretical development and prospect dialysis. Beijing: national academy of administration press.

[3] Wu jianrong. Evaluation model construction and empirical research on urbanization development level [J]. Business economy research, 2014 (3): 17-19.

[4] Wei Hou kai, Wang Yyengqiang, Su Hongjian\&Guo Ye bo (2013). Comprehensive evaluation report on China's urbanization quality. Beijing: institute of urban development and environment, Chinese academy of social sciences, 2-10.

[5] Chongqing statistics bureau. Chongqing statistical yearbook (2017). Beijing: China statistics press.

[6] Zhang Wenming. Analysis of the connotation and path of the "multi governance" environmental governance system [J]. Administrative reform, 2017 (2): 41-45.

[7] Wang Qiaoling. The construction of a beautiful city: connotation, evaluation and countermeasures [C]. Journal of South China University of technology, 2016.

[8] Zeighami E, Zeighami B, Eftekhari A E, KhoshNEVIS P (1976). Effectiveness of the Iranian auxiliary midwife in IUD insertion. Studies in Family Planning, 18-32. 
[9] Elijah M. M. Wanda, Lewis C. Gulula, Gift Phiri. Physics and Chemistry of the Earth (2018). Determination of characteristics and drinking water quality index in Mzuzu City, Northern Malawi. 86-101.

[10] Paulo Morais, Ana S. Camanho. Omega. (2017). Evaluation of performance of European cities with the aim to promote quality of life improvements. 8, 36-51.

[11] Ma Ling, Li Limei, Zhu Hong. Construction and demonstration of evaluation index system of urban comfort in China [J]. Journal of geography, 2018, 73 (4): 755-770.

[12] Chen Ruiqing, Yang Qing, he Ling, pan an'e. study on indicator system of comprehensive, coordinated and sustainable development of cities [J]. National circulation economy, 2017 (10): 55-56.
[13] Zongren. The practical reference of Howard's "garden city" theory to China's urban development [J]. Modern urban research, 2018 (2): 77-81.

[14] Nian Meng, Wang Yao. The impact of natural conditions on the formation and development of Chinese cities [J]. City, 2017 (2): 59-64.

[15] Xiong Guoping, long Di, Wang Yunzhi. Study on the evaluation system and planning strategies of livable cities [J]. Architecture and culture, 2014 (10): 87-90.

[16] Yu Zhonglei, Tang Yuyu, Zhang Hua, Liang Jinshe. Spatial pattern and influencing factors of urban comfort in China $[\mathrm{J}]$. Geographic research, 2016 (9): 1783-1798. 